\title{
Reviews
}

\section{Jan Pilditch, ed. The Critical Response to Katherine Mansfield. Critical Responses in Arts and Letters. 21. Westport, CT: Greenwood Press, 1996.}

Jan Pilditch's selection of critical articles on Katherine Mansfield (KM from now on) is one more added to the range of publications on her done for the last six or seven years. That is, since the hundredth anniversary on the birth of this New Zealand-British short story writer in 1988, some collections of articles on her have seen the light in Europe, America and New Zealand. I am referring to, for example, The Fine Instrument, edited by P. Michel and M. Dupois, Worlds of KM, edited by H. Ricketts, Critical Essays on KM, edited by R. B. Nathan or KM. In from the Margin edited by R. Robinson. But The Critical Response to $K M$ is different from these. It is not a compilation of the last critical trends or studies on her, but one of articles ordered chronologically to show the evolution of criticism.

This book belongs to the collection "Critical Responses in Arts and Letters," whose aim is, in the words of its Series Adviser, Cameron Northouse, "to present a documentary history of highlights in the critical reception to the body of work of writers and artists and to individual works that are generally considered to be of major importance." However ambitious the project of the present volume might appear at first, it is fulfilled in the end, giving us a useful, though probably too general a view of the "critical response" KM received since her early pubiications till very recently, in very different places (New Zealand, France, Great Britain, U. S. A., China) and from very varied critics (most of whom outstanding KM's experts).

The book consists of a Chronology of Mansfield Works, an Introduction by the editor, five sections of articles and a Select Bibliography. The introduction by Jan Pilditch is suitable for the series objectives: she writes a chronological brief account of KM's reception, organised in the same way and following the same points as the different parts of the book do.

Most of the articles included in the first section of the book ("The Early Years") were published during KM's lifetime. They are mainly reviews on the publication of her stories and on the posthumous publication of her Poems and Journal. They coincide in several points: they consider KM a promising, though a bit immature young writer; they compare her with A. Chekhov; and they already qualify her craft as innovative of the short story form. The article by Conrad Aiken, one of the American critics who wrote more articles on $\mathrm{KM}$ at the time, is very well chosen as it is half way between his very positive criticism on Mansfield (see his review on Bliss) and the not so positive criticism on The Doves'Nest and Other Stories. This review on the publication of The Garden Party shows both positive and negative aspects. As a whole, this section gives us an overview of success of KM's works, which makes us think of a manipulated choice or at least of one aimed in some specific direction. 
"Towards Assessment" covers almost thirty years of criticism after Mansfield's death (from 1928 to 1956). This section includes ten articles and their general tone is one of lament on KM's death, a so-called "unfulfilled artist." The analysis of her stories is now deeper, though some articles still have a literary more than a critical value: E. Wagenknecht analyzes technique and associates the stories with psychoanalysis; E. Schneider defends her against the accusation of plagiarism; D. Daiches compares some of her stories with others by J. Joyce; an anonymous reviewer of her collected stories from the $T L S$ makes a comparison between her stories and music and painting. But none is able to separate the analysis of KM's works from her tragic life and neither are E. Bowen, $\mathrm{K}$. A. Porter or J. M. Murry who was later on accused of having contributed a lot to the creation of KM's "legend." The only negative article in the section is the one by Sam Hynes who, basing himself on her personal writings as well, speaks of her not possessing "artistic maturity" and of her short stories being "monotonous," "repetitive," "escapist" and with "immature themes."

Each of the other three chapters of The Critical Response to KM covers about ten years of study on the New Zealander. Criticism evolved much faster then.

"New Approaches" opens with the article of a pioneer in the field of Mansfieldian studies, Ian A. Gordon. According to the following articles this will be a turning point in the evolution of the criticism. It is a comment on the manuscripts acquired by the Government of New Zealand and a comparison with their publication by J. M. Murry in the Journal and Scrapbook. He concludes that he included the material in one or the other indiscriminately and this had given a false image of KM and so created a false "legend" of her life. Gordon rejects Murry's collections as the base for any "critical or biographical work on KM." From this on Murry is very much criticised, as shown in Bateson and Shahevitch's article who analyse "The Fly" as a realist story and reject previous interpretations; or in Christiane Mortelier's who studies the reception of KM in France and the "phases of interest" she attracted since her death. The two other articles included here are also very interesting. Brigid Brophy studies the difficulties the writer had to construct her own identity and the roles that her family and friends played. And Eileen Baldeshwiler analyses her creation of "form," her "technique" and "language" and opposes those critics, common in the 1920's, who characterize her work as the result of her inspiration.

Chapter IV, "Consolidation," copes with the criticism on KM during the 1970's. The first article is a very good description by Margaret Scott of Mansfield's manuscripts, the real source of her work and personal writings. The other articles include studies of the influences on her (apart from the already well-known of Chekhov): T. O. Beachcroft traces Theocritus' Adoniazusae or XVth Idyll in some of her stories. Vincent.O'Sullivan finds several influences: $O$. Wilde, Walter Pater, Joyce, Chekhov, Yeats... and analyzes some images, the epiphanies, her bisexuality and the figure of the father in her stories mainly in relation to these writers. Jeffrey Meyers studies her poem "To Stanislaw Wyspianski" and the relation with and influence of her Polish friend Floryan Sobieniowski. Once more the critics coincide in stressing the negative influences of Murry's publications of $\mathrm{KM}$ and his commentaries on her. The New Zealand critic, novelist and poet $\mathbf{C}$. K. Stead criticizes Murry's analyses of her stories and so does Ruth Elvish Mantz, who made a biography of KM together with Murry.All agree in the need to 
change the course of criticism and disengage the writer from her legend in order to make deeper and new studies of her stories. The already mentioned C. K. Stead makes an account of the phases in which "Prelude" was written. Jean E. Stone analyzes her earliest publications and her early life as a writer in New Zealand. And Cherry Hankin, an expert on $\mathrm{KM}$, goes from her very youthful stories to the most famous and mature ones relating them to other genres, examining the different types of endings and the use of fantasy to contrast with reality.

The last chapter of the book, "One Hundred Years On," includes eight articles which could be grouped in at least three categories: biographies, new focuses and new aspects studied.

The already classical biography of KM by Antony Alpers is present with a portion of one of its last chapters which is an analysis of "At the Bay." And from the more recent biography by Claire Tomalin we get the final chapter about Mansfield's death, the reactions it provoked and her popularity. Susan Gubar's article shows the feminist perspective. Andrew Gurr asks for a more ample perspective to study writers as opposed to the too regional one. Ken Arvedson studies KM's religiousness. Judith Dale starts from her sketches and analizes how the written stories were adapted to radio broadcasts, to the stage and the cinema. Shifen Gong's portion of his dissertation is one of the surprising but not unique studies of KM's influence on Chinese literature. The very last article is itself an homage on KM by the New Zealand Maori novelist and short story writer Witi Ihimaera and, placed here, also an homage and perfect end from the editor Jan Pilditch.

The only aspect left to comment on is the Select Bibliography included at the end of the book. It is divided in four parts: Bibliographical, Biographical, Books, and Essays and Articles. A section usually included in critical studies, Primary Works by the Author, is missing, though this can be compensated by the Select Chronology of Mansfield Works at the beginning of the book. The bibliography is quite comprehensive. It includes most of the references mentioned along the book and some others. However, it may be worthwhile mentioning some works which should not be missing. In the Bibliographical section, and due to the fact that the editor refers to it at the end of the Select Chronology of Mansfield Works, these could have been included: "KM." Twentieth-Century Short Story Explication. Comp. Warren S. Walker. Handem: The Shoe String Press, 1967. 46576; "KM." The New Cambridge Bibliography of English Literature. Ed. I. R. Willison.Cambridge UP, 1972. 653-59; and G. N. Morris. Mansfieldiana. A Brief KM Bibliography. Wellington: The Beltane Book Bureau, 1948. In the Books Section, Van Gunsteren's book KM and Literary Impressionism. Amsterdan: Rapodi, 1990 is missing. And in Essays and Articles an old antecedent of this study on Mansfield's criticism is missing: Jack Garlington. "KM: The Critical Trend." Twentieth Century Literature 2.2 (1956): 51-61, which very well summarizes the criticism till his own day.

There are also some mistakes which could be disconcerting and should be corrected in subsequent editions: in Jeffrey Meyers, "KM: A Bibliography of International Criticism, 1921-1977," there is the number of the volume missing (no. 2). Isabel C. Clarke, KM: A Biography is in the Books section instead of the Biographical one. In The Fine Instrument there is a printing mistake: the year is 1989 instead of 1889. A. Sewell's book KM, A Critical Essay is not written in italics, and it adds "pp 1-32" as if it were an 
article. In Worlds of KM there is another printing mistake: "Ngaere" instead of "Nagare". The page numbers are missing in C. R. Allen, “KM Legend" and in B. Brophy, "Don't Never Forget" (pp. 255-263). In L. Bogan, Selected Criticism, we do not get the publisher's name: Noonday Press. In B. Clarke, "KM's Illness" there is a printing mistake again: the number of the pages is before the date of publication and in J. M. Murry, "In

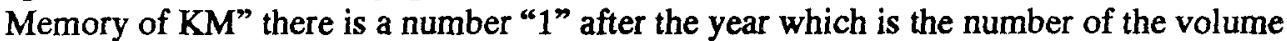
of The Adelphi where the article can be found. Philip Waldron, "KM's Journal" is printed twice and with a different format. Apart from all this the Bibliography is quite good and fulfills the objective of the collection.

The Critical Response to $K M$ is a good collection of articles with no precedent. The articles are well chosen and ordered, they are from critics from many different parts of the world, and in the end we get a general view of the criticism on KM, with both positive and negative commentaries on her along the century. However, it is focused, not without justification, on some of the habitual topics on this writer and it is limiting, as expected, for it cannot deal with absolutely all the criticism on her and it is not a critical study on her reception either. In spite of this it is a useful book for it can open many ways for the study of KM.

Ana Belén López Pérez

\section{A Spanish Gift To Edith Wharton Scholarship}

Edith Wharton. Cartas a Morton Fullerton (1907-1931), (Barcelona, Grijalbo Mondadori, 1995). Ed. Marina Premoli. Translation: Esther Gómez.

Vous qui nous jugez, savez-vous quel boivre nous avons bu sur la mer? (Joseph Bédier)

A recent item of interest to Anglo-American studies in Spain is the publication of a selection of Edith Wharton's letters to her friend and lover Morton Fullerton. Although Edith Wharton is not certainly unknown in Spain -in fact in the last ten years several of her most significant novels and short stories have been translated and published-, this initiative is a welcome surprise as it provides the Spanish readers with details about a woman whose literary achievements, courage, passion and love of life were indeed extraordinary.

Edith Wharton met Morton Fullerton, an American journalist for the London Times and a friend of Henry James, in the spring of 1907. A man of singular attiaction, the author of works like In Cairo, Terres Françaises or Problems of Power, Fullerton was a familiar and yet oddly elusive personality in Parisian circles, culturally sophisticated, with a strong vein of dreamy idealism and a no less positively marked erotic energy and a strong sexual appeal. By the time they made their acquaintance, Wharton's emotional life was going through a difficult time and she felt weary, psychically suffocated and emotionally starved. Her husband had fallen into another nervous depression and it was evident that their marriage, wretchedly unsatisfactory for years, was reaching an end. In 
Paris, as the winter weeks wore on, Wharton and Fullerton's initial attraction soon progressed to intense emotional and physical intimacy. The clandestine affair, which gave Wharton her first glimpse of love after years of frozen marriage, has been considered by Augusta Rohrbach "her next logical step in this author's struggle to live her life to the fullest." And the difficulty the writer had in wrestling a lasting physical and spiritual communion with Fullerton registers in this delightful publication.

For years, their relationship remained hidden to all, critics and friends, with the exception of Henry James and perhaps Gross, Wharton's discreet and devoted housekeeper. In 1962 Wayne Andrews published a small selection from Wharton's unedited diary, "The Life Apart," but it was assumed that the person to whom the journal was addressed was Walter Berry, Edith Wharton's intimate friend. It was Leon Edel who proved otherwise in his biography of Henry James and revealed for the first time the presence of Morton Fullerton.

But it was not only this rather intriguing episode in the life of Edith Wharton that took the critics by surprise. The very existence of these letters is a cause for astonishment; more so when it had long been assumed that the correspondence had been destroyed. Then, in 1980, some three hundred letters from Edith Wharton to Fullerton mysteriously appeared on the market. The collection was purchased by the University of Texas in Austin, and in 1985 the university's Library Chronicle devoted a special issue to this new holding, printing twenty-six letters. Three years later Professor R.B.W. Lewis and Nancy Lewis edited a splendid volume, The Letters of Edith Wharton, among which was the correspondence to Fullerton.

Edith Wharton. Cartas a Morton Fullerton (1907-1931) presents a well-chosen, though somehow small selection of Wharton's letters to Fullerton, concentrating mainly on 1908 and 1909, the period of the passion that overwhelmed her in middle-age. Together with the letters, the volume includes nine entries of her diary "The life Apart" and the fifty-two line poem over a night together in June 1909, "Terminus" - a name chosen to indicate both that the experience occurred in a station hotel and that it marked a temporary end to their relationship (Edith Wharton once read about herself in a review, and wryly recorded the comment, that she was a woman who had never known passion. "Terminus," as well as the letters and diary entries, certainly dispel this legend). Supplementing Edith Wharton. Cartas a Morton Fullerton are notes, an introduction presenting an evocative portrait of Wharton's affair, a chronology, and engaging photographs of key places of Wharton's life -The Mount, her library, Pavillon Colombe, Hyères- and of Morton Fullerton.

Marina Premoli's edition offers the Spanish readers and Wharton aficionados an excellent opportunity to (re)discover the writer's remarkable powers of description, her eloquence, the moods and changes of the relationship, as well as valuable insights on her forceful, vulnerable and energetic personality. Edith Wharton, one might say, was a dialectical woman: the priestess of the life of reason, as she ironically called herself once in a letter, analytical, scrutinizing..., she had also a mystical, Nietzschenian side, eager "to drink fate's utmost at a draught and reach the heart of life". And this aspect, this sensual and wild side - what William James called "the feminine-mystical mind"-, was never 
more evident than in the letters to Morton Fullerton, the most vibrant and openhearted she was ever to write.

The correspondence also detects the aspects of Edith Wharton that Fullerton came to know well when he slyly addressed her as "Cher Ami": The Enlightenment side of Edith Wharton, her interest in biology and in science, her close acquaintance with texts literary, artistic, philosophical, religious, and her historical imagination. Details of her travels, her professional tasks, and her Parisian social and literary life emerge in these letters, sprinkled with allusions to places, books and mythological figures that give us the scope of her great erudition, her knowledge of languages and her intimate familiarity with the classics of ancient and modern literature and with cultural history. The letter she addressed to him on June 8,1908, with its range and variety of quotations and allusions to Milton, Dante or Goethe, is indeed exceptional in the epistolary genre, and can be read and enjoyed as it were a piece of literature. But what the letters make especially evident is Wharton's vibrant nature, her generosity, and her refusal to bargain and calculate "as if love were a game of skill played between antagonists". They reveal that this woman, whose public image was that of the self-contained, was in fact extraordinarily open to experience, "an incorrigible life-lover \& life wonderer", and responsive to the here-andnow of life.

The correspondence enacts the several distinct phases through which the relationship with Fullerton passed: from moments of nearness to torment and grief, fluctuating between expressions of love and desire, camaraderie, apprehension, disenchantment and suffering. The letters oscillate between two opposing geographical places, Paris and Lenox (Massachusetts), and display different narrative moods: from the friendly and the intellectual to the lyrical, from the impassioned to the wretched and the icily conventional. As R.B.W. Lewis and Nancy Lewis have noted, the process is remarkably human: "it is the disclosure of enormous emotional arousal and then of emotional bruising and grief not easily matched in our epistolary annals."

The diary entries are equally eloquent and poignantly human. The journal is addressed to Morton Fullerton in the second person and it deals exclusively with the growth of their relationship in 1908 and 1909 . Edith Wharton apparently conceived it as a narrative with a definite theme, and she gave it a title, "The Life Apart," which she added in parentheses: "L'Ame Close." Although aesthetically the journal cannot be ranked among Wharton's best efforts, there is a wealth of honesty at its core, and behind some cliche-like phrases and exclamations one detects a strength and a fortitude of spirit that were strictly her own. This is particularly clear in her inclusion of Wharton's moving diary entry that, no matter what the cost of her relationship with Fullerton, she felt triumphant satisfaction that she had "drunk the wine of life at last", had been "warmed through and through, never to grow quite cold again till the end...". The entries are interesting from a biographical point of view as they reveal Wharton's contradictory feelings about the ambiguities of desire and identity, about the glory of passion and of how passion may jeopardize individual identity. Like Wharton's correspondence, these diary entries portray these moments of her life that were "lived to the full", moments which in later years were to spring to life again with newfound physical passion in some of her most significant heroines - Charity Royal, Kate Clephane, Helen Olenska. 
Marina Premoli's edition, though perhaps of fairly limited interest among Spanish readers in general, is a true gem for all Edith Wharton enthusiasts. In these pages, carefully selected and meticulously translated, we can appreciate the startling erotic and emotional awakening of the writer, the sudden transition from "the narrow acquiescence in conventional limitations" to a world transformed into beauty and light. To borrow one of her familiar images of the house as an emblem for a character's inner life, this was an experience which, above all, illuminated "the empty rooms full of dust" which her life had been with a light that could never thenceforth be extinguished.

Teresa Gómez Reus

\section{Elizabeth Deeds Ermarth. The English Novel in History: 1840-1895. London and New} York: Routledge, 1997.

Elizabeth Deeds Ermarth's The English Novel in History: 1840-1895 is the third volume in the series generically entitled "The Novel in History" edited for Routledge by Prof. Gillian Beer (Cambridge). The series, which will consist of six volumes, takes an interdisciplinary approach to literary fiction and is informed by recent critical theory. The other two volumes which have as yet been published are David Trotter's The English Novel in History: 1895-1920, and Steven Connor's The English Novel in History: 1950 to the Present.

Prof. Ermarth's book has four chapters. Chapter One, "Narrative and Nature," explains new formations in narrative during the period under study by trying to locate the so-called "pressure points" at which such formations emerged. It focuses on the changes in the view of nature resulting from the secularization of knowledge. According to Ermarth, before mid-century nature is seen as "something hospitable to human aspiration," whereas fifty years later it appears, if at all, as inhospitable to human meaning. "In short," Ermarth says, "Victorian novel more from one to the other of the two constructions of nature that Thomas Carlyle announces in Sartor Resartus: one a nature that is the 'living garment of God', and the other, a nature that is, morally speaking, a 'dead mechanism"' (3). This evolution is explored by reference to literature, science, art, and various other disciplines.

In Chapter Two, "The Idea of History," Ermarth discusses what she calls "the construction of history as a common denominator", a convention describable as the version of the humanist (Kantian, Newtonian) conception of time which underlies Victorian narrative, whether literary, artistic or scientific. Similarly, the humanistic, egalitarian construction of society is dealt with in Chapter Three, "Society as an Entity," and its traces in Victorian narrative located and discussed. This notion of society, which originated in the Enlightenment, is made possible, Ermarth argues, by the convention of historical time explored in the previous chapter.

Ermarth has long been reflecting on the problem of temporality. In her Sequel to History: Postmodernism and the Crisis of Representational Time (Princeton, NJ: Princeton UP, 1992) Princeton UP, 1992) she addressed the postmodern replacement of the convention of historical time for a conception which she then referred to as "rhythmic 
time." Historical time allows for project: it is a neutral and homogeneous temporal medium in which things exist and events take place as if on a road stretching to infinity. This belief, which has dominated Western thought since the Renaissance, is still at the heart of Victorian narrative. Rhythmic time, on the contrary, is an "exploratory repetition" coextensive with the event and which the subject cannot distance itself from, and therefore "any ' $\mathrm{I}$ ' or ego or cogito exists only for the same duration and then disappears [...] or undergoes transformation into some new state of being" (Sequel 53). This postmodern view of temporality is, according to the author, analogous to medieval conceptions. In between, Ermarth says, there is the humanist historical temporality, still latent in nineteenth-century narrative, which she cleverly analyzes in The English Novel in History: 1840-1895.

It is in the latter book's Chapter Four, "Dilemmas of Difference," that Ermarth's feminist standpoint becomes most visible. Here the author treats issues such as class, gender, and other varieties of cultural difference, and the problems they posited in the nineteenth century to the democratic agendas of some realms of English cultural discourse such as narrative fiction and philosophy. This last chapter assumes the concepts of nature, time, and society explained in the other three, and in this sense culminates the argument expounded all along the book and conveys the ideological outlook that dominates Ermarth's approach, which is, as has been anticipated, that of postmodern feminist critical theory.

The way the book is structured - with all four chapters developing an argument, and all of them also firstly stating general ideas which are in turn illustrated-does not favour browsing for particular points, as we are warned in the Preface. This, along with the difficulty of some of the matters discussed, will not contribute to making the book popular among students. It is a book written for the specialist and asks to be read from the beginning to the end, if the reader is to grasp the main argumentative lines.

Those of us who do not possess Prof. Ermarth's erudition cannot help but being impressed by the wealth of sources and information that she utilizes, and even more by the intelligent, original, and insightful way in which this conceptual apparatus is combined to produce a book which is a strong personal statement, both critically and politically. As such, it invites discussion and is bound to generate fruitful controversy if it receives the scholarly attention that, as a doubtless major study of the period in question, it clearly deserves.

Ángel Pérez Vázquez

Román Álvarez \& M. Carmen África Vidal, eds. Translation Power Subversion. Topics in Translation Series, Clevedon, Philadelphia, Adelaide: Multilingual Matters, 1996, vi + 157 pp.

Translation studies represent one of the most attractive fields of research at the moment. It has the advantage of being a relatively new area. Everybody knows that translation dates from thousands of years and has been an essential character in lots of 
historical and cultural events, but the truth is studies on the technique or the process of translation have been restricted for centuries to impressionistic approaches which did not even give enough information to elaborate a set of norms to be applied. Someone simply said they liked or disliked somebody else's translation, an assessment which was, of course, based on questions of taste and had no scientific foundations whatsoever. Translation was seen either as a necessary but disagreeable procedure which had nothing to do with art or linguistics or as a piece of literary recreation which could be liked or not according to whimsical criteria and, of course, could not be described as following any kind of system. This situation has fortunately changed during the last decades and this compilation of articles collected by R. Álvarez and M.A.C. Vidal is a good example of it.

Before I refer to the contents of this volume in more detail I would like to make some comments on the field of translation theory or translation studies. I think it is essential to underline that the turning point in the evolution of this discipline is the change from the vision of translation as a product to the vision of translation as a process. This means a radical transformation and is the marrowbone to the modern theory of translation. There is much more to translation than just replacing words or phrases written in one language with others written in a different language. It is no good looking at a translation as something finished that is going to be praised or rejected, the idea of the one and only correct translation vanishes. R. Álvarez and M.C.A. Vidal express it in the following terms: “...From the eagerness to consider translation as a science or the obsession to give a definitive, prescriptive and sole version of a text, we have moved on to a descriptive outlook which likewise, whether we like it or not, is political" (1). What we are dealing with is, therefore, a very complex intellectual activity which lends itself to different strategies and techniques, none of which can be discarded beforehand. Furthermore, as Álvarez and Vidal suggest above, the study of such techniques and the complexity of translation has also shown aspects such as the effects of translating in a particular way, the impact the translator's choice can have on the readers of the target language and most important, to what extent that choice is, if you allow me the word, innocent. Susan Bassnett says at the end of her article: "we may not burn translators at the stake (though the attacks on Salman Rushdie's translators show that the translator was certainly not seen as an invisible filter) but we are compelled now to recognize the role they play, I am thinking of aspects such as the political use of translation (manipulation, censorship, etc.) (23).

The volume Translation Power Subversion sheds some light on the aspects mentioned in the preceding paragraph along with other equally interesting topics such as pragmatics and cultural translation to mention just a couple, which have been and are still contributing to enlarge the firing range of the field we refer to as translation studies. As regards pragmatics, E. Alcaraz's article offers us a panorama of the different paradigms that have dominated linguistic research in the present century, namely, structuralism, generativism and finally pragmatics. It is the last of these three that is current at the moment, its importance in the field of translation being paramount, specially as it is the source from which the essential notion of pragmatic equivalence has arisen. This new concept of equivalence, in Alcaraz's words “...has a much wider scope of application than semantic equivalence. It includes not only the analysis and comparison of the textual 
meaning of the same passage written in two different languages, but of all the other textual categories (cohesion, thematization, etc.) that may affect their final perception by the receivers of the two languages..." (107)

Along the lines of the previous reference to pragmatics and the enlarged field of application, it is also equally relevant to underline the role of culture, an aspect which is dealt with in J. Franco, O. Carbonell and E. Gentzler's articles, though from different points of view. Thus, J. Franco tries to define what he calls a CSI (culture-specific item). His conclusion is: “...a CSI does not exist of itself, but as the result of a conflict arising from any linguistically represented reference in a source text which, when transferred to a target language, poses a translation problem due to the non-existence or to the different value (whether determined by ideology, usage, frequency, etc.) of the given item in the target language culture" (57). Franco's analysis of three translations of The Maltese Falcon also gives the reader an insight into the workings of the system of cultural translation.

O. Carbonell concentrates on the problems of translation when two mutually 'exotic' cultures are involved. He tells us that in this kind of text "meaning is not located in a source culture or a target culture in an univocal signifying movement; rather, it is being created endlessly in a third cultural space of growing conflict and complexity" (90). Translation, therefore, "trascends the closed circularity of mere imitation ... Translation is a movement 'beyond', establishing a dialectics between here and there, now and then, us and them" (93).

E. Gentzler offers the reader an interesting article on the role of translation as a counter-cultural force through its use in the American journal The Fifties. This article underlines the fact that translation is a means of creating new literary or cultural forms, as is shown by Robert Bly, one of the editors of the journal, whose "work in translation during the fifties played an important role in the development of the new form of poetry" (135) and whose case "supports the thesis that translations played a key role in causing the ensuing cultural crisis" (135).

The last two articles I will refer to are those written by A. Léfevere and T. Hermans. The former concentrates on establishing a relationship between what he considers two ways of rewriting literary texts, namely, translation and the compilation of anthologies. He describes them both in the following terms: "If a translation provides its readers with an image of its original ... the compilation of anthologies, tries to provide its readers/students with an image of literature, a period in a literature, a type, such as drama in general..." (139). He illustrates his reference to anthologies with an analysis of those published in the United States between 1900 and 1988 and reminds the reader of the fact that anthologies are often the first contact readers have with literature and are equally a reflection of the literary canon of their time.

Finally, T. Hermans carries out an exhaustive study of norms in translation. As Hermans puts it "one of the major tasks of the researcher wishing to account for translation as a social practice consists in identifying and interpreting the norms which governed the translator's choices and decisions" (39). Hermans' study shows us that this is by no means an easy task if we bear in mind that we must deal with different cultures and our description of norms will be nothing but an always relatively biased 
interpretation, which leads the reader back to some of the main worries in current research in the field in translation, namely, the importance of politics, the national and international state of affairs, the preeminence of some cultures over others, and so on. The study of translation is therefore, the study of a whole galaxy of factors, as is shown in the excellent group of articles written by an illustrious group of researchers and collected by R. Álvarez and M.A.C. Vidal in Translation Power Subversion.

Víctor Manuel Pina Medina

\section{Michael D. Bristol. Big-time Shakespeare. London: Routledge 1996.}

This is an interesting analysis of the development of Shakespeare's work in the past and present industry of entertainment, which brings together literary, sociological and even economic perspectives. The book is organised in two sections (under the headings The supply side of culture and The pathos of Western modernity) preceded by a twenty-five page introduction.

The initial attitude of the author, Prof. Michael D. Bristol, seems to be to reveal the use of the playwright's image as a potentially marketable decoy for products that are, if anything, only obliquely related to it; from films loosely based on his plays all the way down to credit cards or bank notes that carry his portrait. A business-like manoeuvre with a cultural alibi. However, the first pages of this book err on the side of trivialisation as well. A comparison of Shakespeare to The Beatles, Elvis Presley or Mick Jagger (in a paragraph which is also quoted in the very colourful back cover) looks very much like an 'epater l'Academie' strategy which many may think we have had enough of.

Fortunately, after this flashy introduction, the author gets down to more serious business. The first part of the book opts for a sociological approach to Shakespeare's impact on Western civilization. An interesting conception of his everlasting success as a conflation of the contributions of editors, directors, actors and other members of professional and academic circles throughout the last four centuries gives way to a biographical reference to the most outstanding ones. From Restoration show business entrepreneur William Davenant to 18th century actor and theatre manager David Garrick; publisher Jacob Tonson and his rewriting-Shakespeare conflicts with Alexander Pope and the reputed scholar Lewis Theobald; with the latest conflictive step being Kenneth Branagh's current cinematic simplifications. The economic and social conditions of the culture entertainment industry do not seem to have changed that much after all this time.

Several critical issues are at stake here concerning Shakespeare's massive appeal: the way certain literary specialists reject his versatility at crossing the bridge between popular and high culture (which do not have to be mutually exclusive); the dialogical relationship between the moment of creation and the period of representation/reception; and the semantic potentiality of his work and how it can be manipulated by subsequent structures of power. Prof. Bristol dismisses the intention of the author as a key factor in establishing meaning, but does not join the poststructuralist mourning either. The text value itself, which is indebted to the author, but also to its multiple readings and performances, determines its unrivalled emancipatory strength. 
The second part of this book will be more attractive for the literary scholar, who can find an in-depth analysis of three plays (The Winter's Tale, Othello and Hamlet) and its connections with current areas of discussion. In the chapter on The Winter's Tale, Prof. Bristol foregrounds the distortion of time as the playwright's device to portray contemporary social complexity, whereas Othello is considered a radical attempt to reveal the unlawful use of social institutions (marriage in this case). More interesting, from my point of view, is his reflection on the intelectual unacceptability of prominent conceptual features of these plays: the chauvinist picture of a passive female role and, in Othello, a blatantly racist presentation of character. Bristol sides with Bloom against the opinions of the so-called 'school of resentment': it is impossible to make a feminist or anti-racist reading of them, but their intrinsic literary value still makes Shakespeare the pivotal figure of the Western Literary Canon. The chapter on Hamlet is a grounded acknowledgement of the character as the archetypical 'genius' of Western modernity, although the relevance of using a comic strip (Calvin and Hobbes) to illustrate contemporary quotations of the play is hardly justifiable, specially for those of us who had never heard of it.

Shakespeare's skill at entrepreneurship is nothing he should have had to apologise for. Neither should the author of this book for its commercial intentions. One would recommend leaving aside an academic reluctancy to this kind of presentation; reading this text will certainly contribute to our understanding of this world-wide academic, social and economical phenomenon which, whether we like it or not, Shakespeare has (been) turned into.

John D. Sanderson

\section{Daniel Statman, Moral Dilemmas. Amsterdam, Rodopi, 1995. 174 pp. Col. «Value Inquiry Book Seriesm, $n^{2} 32$.}

We must begin by considering what moral dilemmas are for the author of this very interesting, although not completely successful, work, Daniel Statman. A main problem is his very definition of a moral dilemma, and the initial picture of all his research project, a long and winding road around the project of reaching a strong and more rationalistic theory of morals:

"Moral dilemmas are puzzling situations, where agents seem to be under an obligation both to do, and to refrain from doing, a specific act. The possibility that such situations exist has been a matter of great controversy in the last decade. Some philosophers have argued that dilemmas are possible and, therefore, real. This view is often connected to other prevalent ideas in contemporary ethics, the idea of moral luck, and the «anti-theory» trend. Other philosophers have argued that dilemmas are impossible. In this view, we can never be under two real, «all-things-considered» obligations. This latter view is the one endorsed in the present book. I seek to show that dilemmas do not point to any inconsistency in our ethical reasoning nor do they justify giving up the idea of an ethical theory. This does not imply that dilemmas are not troubling, or that they are not the source of justifiable strong negative feelings. They are, and I try to show why. If the argument of the book is sound, it will 
constitute a modest contribution to a more «rationalistic» view of ethics and to what Robert Louden recently called «the re-affirmation of moral theory» (1992).“ [p. 3]

Beside the general difficulties caused by the problematic character of the very researching point of this work, there are other precise objections to raise, for example, the complete disregard of a major figure in contemporary ethics, Lawrence Kohlberg, who makes a deep development and use of moral dilemmas inside his theory of human moral growth. But this is not the only absence.

In the first chapter, the author approaches what is one of his main objectives: to show that moral dilemmas in reality are not such, that they do not exist properly. One of his key arguments is that the difference between the supposed moral dilemmas and the daily moral conflicts rests in the quantity of the "wrong" that purportedly it is at stake in each situation, but it does not depend on any specific property of the situation.

From this point of view, what in reality seems to occur with the agents in a moral dilemma is that are found in an uncertainty situation insofar as the real nature of the options that have before himself is unknown. It is this lack of definition and not the same nature of the situation what seems to be in the origin of the appearance of a dilemma. Again, Daniel Statman tries a rationalistic solution to the ethical problem constituted by moral dilemmas, forgetting that it can have other approaches. For example, the modern theory of moral education has indicated clearly that an individual can deal with a moral dilemma through no fault of information but due to lack of motivation, to lack of an adequate development of the moral will.

The rationalism of the author of this work adopts its maximum expression in the second chapter, where a notion appears that, though seems to discuss the issue of the moral dilemmas, in reality considers it solved. Thus, the basic thesis of Daniel Statman in this work is that a correct solution exists, and only one, for each situation morally conflicting. This Statman calls "The Right Answer Thesis".

Without looking at the problems of asserting the existence of a principle of this type, Statman says to us that this principle consists of two parts: the first part asserts that moral dilemmas have a right answer, and the second asserts, it is evident, that moral dilemmas are not real but constitute distorted situations, mainly due to lack of information in the agents.

The principal objection against the principle of right response to the moral dilemmas formulated by the author of this work arises from utilitarianism. According to this theory in its contemporary formulations there is no rational solution to a moral dilemma because the values in conflict are incommensurable. The only one solution that the author considers is not to change of strategy in the treatment of the moral dilemmas, resigning to his hard theory of rationality, or at least widening it, but intends to escape to the objection of the incommensurability of moral preferences establishing something obvious, this is, that the incommensurability does not prevent the comparability.

As Statman himself indicates, the objection of the incommensurability in reality is putting in question the same purpose in all his research project: the construction of an ethical theory in strong sense and with a clearly rationalistic character. 
It is interesting to this respect that, though Daniel Statman handles a wide classic and contemporary bibliography, within it he includes for example James Griffin (Whitechapel Professor at Oxford University); however he does not use the argument of this same author in connection with the problems of the so-called strong ethical theories.

Regardless of these problems mentioned, and if we must emphasise some especially meritorious point in this work, indeed this would be its idea according to which "the ongoing discussion over the so-called reality of moral dilemmas is not a genuine one, or at least, is far less interesting and important than is usually thought." (P. 149) This interesting idea connects with the position, formulated for example by Dale Jamieson, according to which the abusive use of moral dilemmas in the contemporary ethical theory, darkens more than clarifies its work.

Beyond this criticism to the contemporary role of moral dilemmas is the problematic character of the global project that this work defends: the construction of a new ethical rationality in strong sense. This proposal implies to introduce Ethics in a long and winding road, a distant way to complete, and maybe impossible, rationality.

José L. Tasset Professor of Ethics at A Coruña University, Spain 